\title{
MATHEMATICAL MODELLING FOR PREDICTING THE THERMAL PERFORMANCE OF SOLAR DISTILLATION UNITS
}

\author{
MOHAMMED A. HABIB and SHEDID H. SHAMS EL-DIN. \\ MECHANICAL POWER ENG., FACULTY OF ENG. \\ MENOUFIYA UNIVERSITY, SHEBIN EL-KOM, EGYPT
}

\section{ABSTRACT:}

A single basin-type solar still with an area of $0.65 \mathrm{~m}^{2}$ is constructed in Menoufiya University and tested under the transient operation conditions. The hourly variation of basin water, glass cover and ambient temperatures, as well as the evaporative mass transfer rate are measured during the operation. A thermal model has been developed for predicting the performance of the unit. The model is based on the outdoor measurements of distillate water collected from the still and the heat balance equations. Experimental data for evaporative mass transfer rate, basin-water temperatures, glass cover temperatures and heat transfer coefficients have been compared with the predictions data obtained from the model. The comparisons are also made with the experimental data using three mathematical models: Turbulence, McAdams, and Adhikari models. The Grashof number was ranged from $5.13 \times 10^{3}$ to $2.10 \times 10^{5}$.

It is found that the general trends of the model predictions are in a reasonable agreement with the experimental data. However, the predictions for the solar distillation are found to be sensitive to the empirical correlation employed to describe the unit performance. For the three models tested, the turbulence model overpredicted the evaporative mass transfer rates and heat transfer coefficients. The other two models, McAdams and Adhikari, underpredicted these rates and coefficients. The basin water and glass cover temperatures have the predictions inverted. It is concluded that the present model has the better predictions of the still performance compared with other models. Particular care, however, must be taken in the choice of the heat transfer correlation necessary for calculations. 
Water is evaporated in the earth's surface through the absorption of solar radiation. The water vapor is transported by means of the air currents until the mixture cools to dew point temperature and, then the water vapor is condensed. The basin-type solar still duplicates this natural process on a small-scale [1]. Where only saline water is available, with high levels of solar radiation as for Egyptian land, the basin-type solar still may be an important supplier of fresh water for human or animal consumption in remote areas or arid zones.

The operation of the solar still is governed by various heat transfer modes. These modes occur within the unit, referred to as internal transfer, and between the unit and the environment, referred to as external transfer. Free convection and radiation are the predominant modes of heat transfer inside the unit. A very small amount of energy is also lost to the ground or atmosphere due to heat conduction through the base or cover. The difference between the modes of heat transfer in these two regions is that, while, within the distillation unit free convective heat transfer occurs simultaneously with evaporative mass transfer, no such mass transfer occurs outside it. Radiative heat transfer occurs in both the regions along with other modes. However, accurate methods for predicting different modes of heat transfer within the still unit are required. In order to predict convective heat transfer coefficient, prediction of convective heat transfer rate is important. Moreover, the convective heat transfer rate is usually used to calculate the evaporative heat transfer rate, which is employed in calculating the mass of distillate and thermal efficiency of the unit. Therefore, any inaccuracy in computing convective heat transfer coefficient will affect simultaneously of the mass of distillate and thermal efficiency. As a result the choice of the suitable heat transfer correlation is essential for accurate prediction of the performance and hence, designing the unit.

For the case of heat transfer by free convection, the Nusselt number is related to the Grashof and Prandtl numbers, i.e.:

$$
\mathrm{Nu}=\mathrm{C} \cdot(\mathrm{Gr} \cdot \operatorname{Pr})^{\mathrm{n}}
$$

Where $C$ and $n$ are empirical constants. Several models based on the correlation (1) used to predict the convective heat transfer coefficients and consequently, hourly and daily evaporative mass transfer rates in solar distillation units have been proposed [2-9]. A summary for these correlations is presented in Table 1. Jakob [2] has arrived at the above expression by correlating the experimental data for heat flow from the 
Table 1: Summary of the convective heat transfer correlations used for solar distillation units.

\begin{tabular}{|c|c|c|c|c|c|}
\hline $\begin{array}{l}\text { Model } \\
\text { No. }\end{array}$ & Author & Correlation & $\begin{array}{l}\text { Operating } \\
\text { conditions }\end{array}$ & $\begin{array}{l}\text { Eqn. } \\
\text { No. }\end{array}$ & Ref. \\
\hline 1 & Jakob & $\begin{array}{l}N u=1.0 \\
N u=0.210 \mathrm{Ra}^{1 / 4} \\
N u=0.075 \mathrm{Ra}^{1 / 3}\end{array}$ & $\begin{array}{c}\mathrm{Gr}<10^{3} \\
10^{4}<\mathrm{Gr}<3.2 \times 10^{5} \\
3.2 \times 10^{5}<\mathrm{Gr}<10^{7}\end{array}$ & $\begin{array}{l}\text { (2) } \\
\text { (3) } \\
\text { (4) }\end{array}$ & [2] \\
\hline 2 & McAdams & $\begin{array}{l}\text { for hot surface } \\
\text { facing upward: } \\
\mathrm{Nu}=0.54 \mathrm{Ra}^{1 / 4} \\
\mathrm{Nu}=0.15 \mathrm{Ra}^{1 / 3} \\
\text { for hot surface } \\
\text { facing downward } \\
\mathrm{Nu}=0.27 \mathrm{Ra}^{1 / 4}\end{array}$ & $\begin{array}{l}10^{4}<\mathrm{Ra}<10^{7} \\
10^{7}<\mathrm{Ra}<10^{11} \\
10^{5}<\mathrm{Ra}<10^{11}\end{array}$ & $\begin{array}{l}(5) \\
(6) \\
(7)\end{array}$ & [3] \\
\hline 3 & Dunkle & $\mathrm{Nu}=0.075 \mathrm{Ra}^{1 / 3}$ & $3.2 \times 10^{5}<\mathrm{Gr}<10^{7}$ & $(8)$ & [4] \\
\hline 4 & Adhikari & $\begin{array}{l}\mathrm{Nu}=0.21 \mathrm{Ra}^{1 / 4} \\
\mathrm{Nu}=0.1255 \mathrm{Ra}^{1 / 3}\end{array}$ & $\begin{array}{l}10^{4}<\mathrm{Gr}<2.51 \times 10^{5} \\
2.51 \times 10^{5}<\mathrm{Gr}<10^{7}\end{array}$ & $\begin{array}{c}(9) \\
(10)\end{array}$ & {$[6,7]$} \\
\hline 5 & Shawagfeh & $\begin{array}{l}\text { using bulk motion } \\
\text { model: } \\
\text { hcw }=0.075 \mathrm{Ra}^{\prime} \\
\text { using Chilton- } \\
\text { Colburn model: } \\
\text { hcw }=0.051 \mathrm{Ra}^{\prime}\end{array}$ & $\begin{array}{l}10<\mathrm{Ra}^{\prime}<35 \\
10<\mathrm{Ra}^{\prime}<35\end{array}$ & (12) & [8] \\
\hline 6 & Kumar & $N u=0.0322 R a^{0.414}$ & $\begin{array}{c}1.794 \times 10^{6}<G r<5.72 \\
4 \times 10^{6}\end{array}$ & (13) & [9] \\
\hline
\end{tabular}

vater surface in the upvard direction. The values of $C$ and $n$ in various ranges of the Grashof number are given in Table 1. Malik et al. [10] have recommended to use the empirical correlations reported by MeAdams [3] for calculating convective heat transfer zocfficients in the basin water. The recommended correlations are introduced depending on the direction of heat flow. Dunkle [4] employed the empirical constants developed by Jakob [2] for free convection of air in an enclosure, assuming it to describe the conditions inside the unit. Tiwari et al. [5] studied the effect of inclination of the condensing surface on the heat and mass transfer coefficient taking the same correlation as proposed by Dunkle [4]. Adhikari et al. $[6,7]$ modified the values of these coefficients in simulated conditions and reported that the Dunkle model behaves well in the lower water temperature ranges $\left(40-50{ }^{\circ} \mathrm{c}\right)$. 


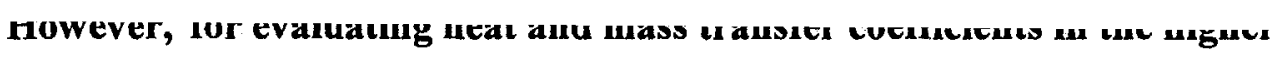
ranges of water temperatures, these coefficients were modified as shown in Table 1. Shawaqfeh and Farid [8] expressed the convective heat transfer coefficient as a function of modified Raleigh number: hcw $=\mathrm{C} \cdot \mathrm{Ra}^{\prime n}$, considering the turbulence model in their work. The constant $n=1 / 3$ was retained in the latter relation, while a new constant $C$ was evaluated. They concluded that the Dunkle model overpredicts values of evaporation rates by about $40 \%$. Clark [11] developed a mathematical model for an operating temperature range between 55 and $95^{\circ} \mathrm{c}$ in simulated conditions. He also found that values of coefficients for convective mass transfer reduce to half that of Dunkle model. An empirical correlation based on the measurements of the mass of distillate was proposed by Kumar and Tiwari [9] to predict the hourly heat and mass transfer coefficients inside the unit. The range of Grashof number is somewhat limited to use and the accuracy seems to be higher than they estimated due to neglecting some observations during measurements.

It appears that most of the above models are based on simulated studies and only a few of them include comparison with true measurements $[8,9]$. On the other hand, the correlation proposed by Dunkle [4], which used by most investigators, was developed from experiments of free convection in the absence of evaporation. The present work proposes a mathematical model for predicting the thermal performance of solar distillation units. Evaporative mass transfer rate, heat transfer coefficient, thermal efficiency, basin water and glass cover temperatures were calculated by the model and compared with the experimental data. The results have also been compared with the predictions of McAdams and Adhikari models, correlations: (5) and (9) respectively. The Grashof number ranged from $5.13 \times 10^{3}$ to $2.10 \times 10^{5}$.

Two different methods for estimating the unit performance are considered:

(a) Using correlation (1) with new coefficients $C$ and $n$; evaporative mass model, and

(b) Using correlation (1) with coefficient $n=1 / 3$ and a new coefficient $C$; turbulence model.

\section{2- THERMAL MODEL:}

The thermal model has been developed to provide better prediction for evaporative mass transfer rate, heat transfer coefficient, thermal efficiency, basin water and glass cover temperatures. These parameters are obtained by introducing new values for the constants $C$ and $n$ in correlation (1) based on the outdoor measurements of distillate water 
collected from the still, besides basin water, glass cover and air temperatures. This new correlation has again been used to calculate the theoretical values of the previous parameters. The following assumptions have been made:

1-The temperature gradients across the glass cover and water depth are neglected.

2-The surface areas of the glass cover and water surface are equal.

3-The incident solar radiation on a horizontal surface is assumed.

\section{2-1. Evaporative Heat Transfer Coefficient:}

The solar radiation absorbed by the water as a heat is transferred to the cover by evaporation, convection and radiation. The rate of heat transfer from the water surface to the glass cover by evaporation can be estimated by:

$$
\text { gew }=\operatorname{hew}(\mathrm{Tw}-\mathrm{Tg})
$$

where hew is the evaporative heat transfer coefficient from the water surface to glass cover, $T w$ and $T g$ are the water and glass cover temperatures, respectively. [10] as:

The evaporative heat transfer rate is also given by Malik et al.

$$
\text { qew }=16.273 \times 10^{-3}(\mathrm{Pw}-\mathrm{Pg}) \cdot \mathrm{hcw}
$$

where $P w$ and $P g$ are the water vapour pressures at the basin water and glass cover temperatures, respectively.

\section{2-2. Convective Heat Transfer Coefficient:}

The rate of heat transfer from the water surface to the glass cover by convection is given by:

$$
\mathrm{qcw}=\mathrm{hcw}(\mathrm{Tw}-\mathrm{Tg})
$$

where hcw is the convective heat transfer coefficient from the water surface to the glass cover. The value of $\mathrm{hcw}$ is found from correlation (1), i.e.: 


$$
\begin{array}{cc}
\mathrm{Nu}=\frac{1 \mu \mathrm{wr} \cdot \mathrm{ur}}{\mathrm{kf}}=\mathrm{C}(\mathrm{Gr} \cdot \operatorname{Pr})^{\mathrm{n}} \\
\text { where: } \quad \mathrm{Gr}=\frac{\mathrm{g} \beta \rho^{2}(\mathrm{df})^{3}\left(\Delta \mathrm{T}^{\prime}\right)}{\mu^{2}} \\
\operatorname{Pr}=\frac{\mu \cdot \mathrm{Cp}}{\mathrm{kf}}
\end{array}
$$

and

$$
\Delta T^{\prime}=(T w-T g)+\left[\frac{(P w-P g)(T w+273)}{268.9 \times 10^{3}-P w}\right]
$$

\section{2-3. Radiative Heat Transfer Coefficient:}

The radiative heat transfer rate from the water surface to the glass cover is given by:

$$
\mathrm{qrw}=0.9 \sigma\left(\mathrm{T}_{\mathrm{w}}^{4}-\mathrm{T}_{\mathrm{g}}^{4}\right)
$$

and the radiative heat transfer coefficient is determined from:

$$
\text { hrw }=0.9 \sigma\left(\mathrm{T}_{\mathrm{w}}^{2}+\mathrm{T}_{\mathrm{g}}^{2}\right)(\mathrm{Tw}+\mathrm{Tg})
$$

\section{2-4. Evaporative Mass Transfer Rate:}

The evaporative mass transfer rate of water is given by:

$$
\mathrm{Mw}=\frac{\mathrm{qew} \cdot \mathrm{x} 3600}{\mathrm{hfg}}
$$

Using eqn (17), eqn (15) can be rewritten as:

$$
\text { qew }=16 \cdot 273 \times 10^{-3}(\mathrm{Pw}-\mathrm{Pg}) \cdot\left(\frac{\mathrm{kf}}{\mathrm{df}}\right) \cdot \mathrm{C}(\mathrm{Ra})^{\mathrm{n}}
$$

where $\mathrm{Ra}=\mathrm{Gr}$.Pr

Equation (23) can be rewritten using eqn (24) as follows: 


$$
\mathrm{Mw}=16.273 \times 10^{-3}(\mathrm{Pw}-\mathrm{Pg})\left(\frac{\mathrm{kf}}{\mathrm{df}}\right) \cdot C \cdot(\mathrm{Ra})^{\mathrm{n}}\left(\frac{3600}{\mathrm{hfg}}\right)
$$

Therefore, eqn (25) may be written as:

$$
\mathrm{Mw} / \mathrm{R}=\mathrm{C}(\mathrm{Ra})^{\mathrm{n}}
$$

where the magnitude of $R$ is defined by the following eqn:

$$
\mathrm{R}=16.273 \times 10^{-3}(\mathrm{Pw}-\mathrm{Pg}) \cdot\left(\frac{\mathrm{kf}}{\mathrm{df}}\right) \cdot\left(\frac{3600}{\mathrm{hfg}}\right)
$$

For transient operation conditions, the values of basin water and glass cover temperatures vary significantly because of the variations in climatic conditions and consequently $\mathrm{Mw}$ and Ra are also vary.

\section{2-5. Energy Fractions:}

The relative magnitudes of each mode of heat transfer, the heat transfer by evaporation, convection and radiation, are expressed as a fraction of the total energy transferred as follows:

$$
\begin{aligned}
& \text { fee }=\left(q e w / q_{t w c}\right) \\
& f e c=\left(q c w / q_{t w c}\right) \\
& \text { fer }=\left(q r w / q_{t w c}\right)
\end{aligned}
$$

where the total energy transfer rate can be determined using equations (14), (16) and (21):

$$
q_{\text {twc }}=q e w+q c w+q r w
$$

\section{2-6. Internal Heat transfer Coeffieient:}

The internal heat transfer coefficient between the water and glass cover is given by:

$$
\mathrm{Ui}=\text { hew }+ \text { hcw }+ \text { hrw }
$$


simuar calcuations for tne relative magnituues vi cacin muc ve heat transfer coefficient, expressed as a fraction of the internal heat transfer between the water and glass cover, can be obtained.

\section{2-7. Heat Balance Equations:}

The heat balance equation on the water inside the basin may be expressed as:

$$
\mathrm{Hs} \cdot\left(\tau_{\mathrm{g}} \cdot \alpha_{\mathrm{w}}\right)=\mathrm{Cw} \cdot \frac{\mathrm{dTw}}{\mathrm{d} \tau}+(\mathrm{qew}+\mathrm{qcw}+\mathrm{qrw})+\mathrm{q}_{\mathrm{b}}
$$

The heat transfer rate to base of the basin and sides is given by:

$$
\mathrm{q}_{\mathrm{b}}=\mathrm{hb} \cdot(\mathrm{Tw}-\mathrm{Ta})
$$

The heat transfer coefficient through the base and sides is given by [12]:

$$
\mathrm{hb}=\left[\frac{1}{\mathrm{ho}}+\sum_{\mathrm{i}=1}^{\mathrm{n}} \frac{\mathrm{x}_{\mathrm{i}}}{\mathrm{k}_{\mathrm{i}}}\right]^{-1}
$$

where $x_{i}$ and $k_{i}$ are the thickness and thermal conductivity of the different layers of the basin, still material and insulation layer. The value of ho is calculated from the conventional correlation relating to Nusselt and Rayleigh numbers for flat-plate with the hot side facing upward [13].

The heat balance equation on the glass cover may be written as:

$$
\mathrm{q}_{\mathrm{ga}}=\mathrm{Hs}-\alpha_{\mathrm{g}}+(\mathrm{qew}+\mathrm{qcw}+\mathrm{qrw})
$$

or:

$$
\mathrm{Hs} \cdot \alpha_{\mathrm{g}}+(\mathrm{qew}+\mathrm{qcw}+\mathrm{qrw})=\mathrm{q}_{\mathrm{ga}}+\mathrm{cg} \cdot \frac{\mathrm{dTg}}{\mathrm{d} \tau}
$$

where $\mathrm{q}_{\mathrm{ga}}$ is the heat transfer rate from the transparent cover to environment.

\section{2-8. External Heat Transfer Coefficient:}

The rate of heat transfer from the transparent cover to environment depends on convection by air circulation and on radiation 
to sky. The convection portion is taken as a function of the wind speed. Radiation to the sky depends on the effective sky temperature, which is taken as $11^{\circ} \mathrm{c}$ less than the ambient temperature [14], i. e.:

$$
\mathrm{q}_{\mathrm{ga}}=\mathrm{q}_{\mathrm{cga}}+\mathrm{q}_{\mathrm{rgs}}
$$

and

$$
\mathrm{Ts}=\mathrm{Ta}-11
$$

The convective rate of heat transfer from the glass cover to air is given by:

$$
\mathrm{q}_{\mathrm{cga}}=\mathrm{hw} \cdot(\mathrm{Tg}-\mathrm{Ta})
$$

The wind heat transfer coefficient related to the wind speed is given by the following empirical correlation [8]:

$$
\text { hw }=2.8+3.0 \cdot \mathrm{V}
$$

The radiative heat transfer rate between the glass cover and the sky is given by:

$$
\operatorname{qrgs}=\varepsilon_{\mathrm{g}} \sigma\left[\mathrm{T}_{\mathrm{g}}^{4}-\mathrm{T}_{\mathrm{s}}^{4}\right\rfloor
$$

The heat transfer coefficient between the glass cover and environment is given by:

$$
\mathrm{U}_{\mathrm{o}}=\text { hcgs }+ \text { hrgs }
$$

The convective heat transfer coefficient due to wind referenced to the sky temperature is written as [15]:

$$
h c g s=h w \frac{(\mathrm{Tg}-\mathrm{Ta})}{(\mathrm{Tg}-\mathrm{Ts})}
$$

The radiative heat transfer coefficient between the glass cover and the sky is given by:

$$
\operatorname{hrgs}=\varepsilon_{\mathrm{g}} \sigma\left(\mathrm{T}_{\mathrm{g}}^{2}+\mathrm{T}_{\mathrm{s}}^{2}\right)(\mathrm{Tg}+\mathrm{Ts})
$$

The overall upward heat flow factor between water and environment is given by [15]: 


$$
\mathrm{Ut}=\left\lfloor\left(\frac{1}{\mathrm{Ui}}\right)+\left(\frac{1}{\text { Ar.Uo }}\right)\right\rfloor
$$

where $\mathrm{Ar}$ is the glass plate to water surface area ratio, $\mathrm{Ar}=\mathrm{Ag} / \mathrm{Aw}$.

\section{2-9. Still Efficiency:}

The still daily operational efficiency is given by:

$$
\eta_{\text {thd }}=\frac{\sum_{i=1}^{N} \text { gew }}{\sum_{i=1}^{N} H s}
$$

Thermophysical properties of the humid air have been evaluated at the average temperatures of evaporation and condensation surfaces using the empirical correlations introduced by Adhikari et al. [7]. Calculated values of hew with the aid of eqns (14) and (23) were checked using eqns (14) and (15).

In the transient analysis of the solar still, initial values of the measured basin water and glass cover temperatures were employed in eqns: (33) and (37), respectively. The time interval $\Delta t$ was taken as one hour. Predictions of the basin water and glass cover temperatures were then calculated at the end of each time interval.

\section{3- EXPERIMENTAL SET-UP:}

The experiments were carried out at Shebin El- Kom, Egypt during the month of July 1999. A schematic diagram of the basin-type solar still constructed from galvanized iron sheet is shown in Fig. 1. The heights of the front and back walls were $0.16[\mathrm{~m}]$ and $0.30[\mathrm{~m}]$, respectively, forming a glass cover inclination angle of $20^{\circ}$ with respect to the horizontal. To perform the experiment with a minimum storage effect, the water level in the basin was adjusted at $2[\mathrm{~cm}]$ depth. The interior surface of the basin was painted black to enhance the absorption of solar energy. An inclined rectangular channel was welded at the inside long wall of the still for condensate collection. A rectangular window of a glass sheet, $3[\mathrm{~mm}]$ thickness, was placed at the upper side of the still and tightened using a rubber stick to avoid vapor leakage. The transparent cover permits a major portion of the solar radiation to reach the basin water. The incident solar energy inside the still was maintained using insulation material at its bottom and walls. A wooden box was used to envelop the still and insulation. 


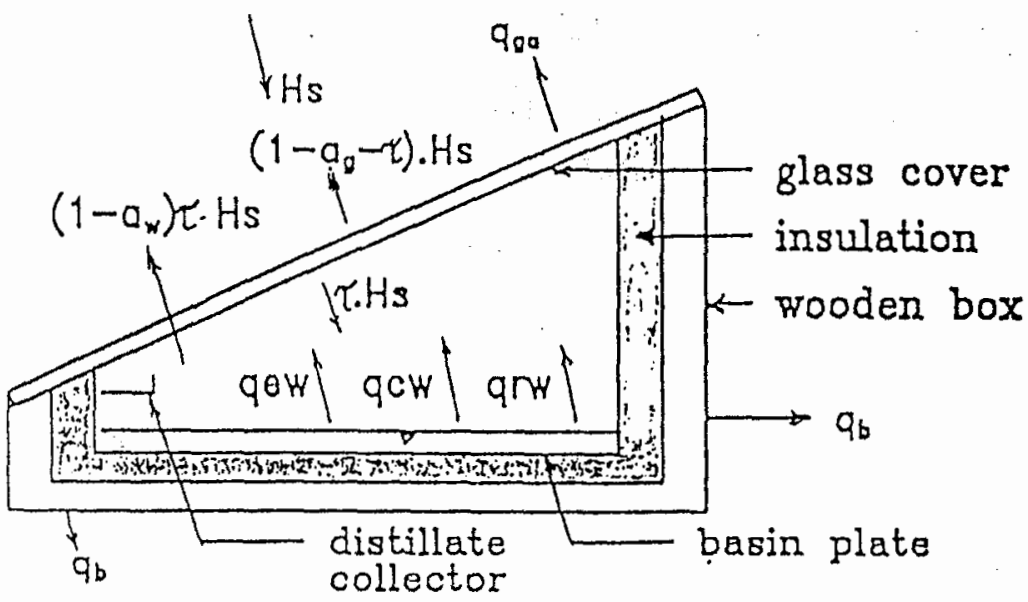

Fig. 1: Schomatic diagram of the experimental

The basin water and glass cover temperatures were measured by calibrated copper-constantan thermocouples connected to sensitive digital millivoltmeter with an accuracy of $\pm 0.1^{\circ} \mathrm{c}$. Water temperatures were measured at three different positions distributed at equally spacing in the middle of the basin and the average value was considered. Another thermocouple was used to measure the ambient air temperature and placed near to the still unit. Heat balance equation, eqn (33) was used to determine the solar radiation intensity. The production rate of distilled water was measured by a graduated cylinder at a regular interval of one hour from 9 A. $M$. and continued until 19 P. M. with an accuracy of 1.0 [ml.].

\section{4- RESULTS AND DISCUSSION:}

Based on the proposed mathematical model, the hourly variation of the evaporative mass transfer rate, heat transfer coefficient, overall upward heat flow factor, still efficiency as well as basin water and glass cover temperatures are shown in Figs 2 to 13. For comparison, on the same figure the experimental data for these parameters are also presented. The results of the still daily productivity and efficiency are given in Table 2. The average absolute deviation $A A D \%$ was used for selecting the best correlation that describes the still performance.

\section{4-1. Still Evaporative Mass Transfer Rate:}

Figures 2,3 and 4 show a comparison between the predicted and measured evaporative mass transfer rate results. The variation of $\mathrm{Mw} / \mathrm{R}$ with Ra for the evaporative mass and turbulence models is shown in Fig. 2. The results were also plotted for McAdams and Adhikari models. The empirical correlations obtained from the best fit are: 


$$
\mathrm{Mw} / \mathrm{R}=0.669 \times \mathrm{Ra}^{0.3322}
$$

and, for turbulence model:

$$
\mathrm{Mw} / \mathrm{R}=0.699 \times \mathrm{Ra}^{1 / 3}
$$

Correlations (48) and (49) are obtained for Grashof number ranging from $5.13 \times 10^{3}$ to $2.10 \times 10^{5}$. It may be observed from Fig. 2 that correlation (48) depict a reasonable agreement between predicted and experimental values of $\mathrm{Mw} / \mathrm{R}$, whereas correlation (49) results in overprediction. The average absolute deviations of $25.9 \%$ and $28.4 \%$ were computed for evaporative mass and turbulence models, respectively. Figure 2 also shows that both of McAdams and Adhikari models substantially underpredict the values of $M w / R$ compared to other models. The computed values of the average absolute deviations of 64.2 $\%$ and $86.1 \%$ were recorded for McAdams and Adhikari models, respectively. Hence, correlations (5) and (9) may not be taken as a good approximation for predicting convective heat transfer coefficients in solar distillation units in regions like Egypt. The discrepancy observed between the measured and predicted results may be due to the assumptions considered in setting up the model. Some inaccuracy arises from cover losses to ambient at a variable wind speed, a factor that increases at noon periods. The disagreement between the measured and predicted results using McAdams and Adhikari models may be due to neglect the effect of weather conditions during the simulated experiments compared to outdoor conditions.

Correlations: (48) and (49), as well as McAdams and Adhikari models were used to predict the evaporative mass transfer rates for the still unit. Figure 3 shows the hourly measured and predicted Mw using different models. In Figure 4, a comparison between the measured and predicted $\mathrm{Mw}$ are presented. The hourly evaporative rate predicted by present model, correlation (48), was in a reasonable agreement with the measured values, except for the individual values in the morning (at $9 \mathrm{~A}$. M.) and in the evening (at 19 P. M.). At these intervals, the solar intensity was quite low which results in low evaporation rates. These low rates cause an increasing in the computations of the average absolute deviation. Kumar and Tiwari [9] rejected some observations at these intervals to obtain higher accuracy. On the other hand, the predicted values of $\mathrm{Mw}$ using turbulence model, correlation (49), were relatively higher than that measured. However, a tendency for the very low prediction of evaporation rate using McAdams and Adhikari models is again evident in Figs. 3 and 4. Table 2 presents a comparison between the measured and predicted still daily productivity using different 
models. The results for the daily efficiency are also given in Table 2 . It is seen that the evaporative mass model gives better predictions compared with the other models.

Table 2: Comparison between the measured and predicted still daily productivity and efficiency.

\begin{tabular}{|c|c|c|c|c|c|c|c|c|c|}
\hline \multirow{3}{*}{$\begin{array}{l}\text { Para- } \\
\text { meter }\end{array}$} & \multirow{3}{*}{ Meas. } & \multicolumn{4}{|c|}{ Present models } & \multirow{2}{*}{\multicolumn{2}{|c|}{$\begin{array}{l}\text { McAdams } \\
\text { model }\end{array}$}} & \multirow{2}{*}{\multicolumn{2}{|c|}{$\begin{array}{l}\text { Adhikari } \\
\text { model }\end{array}$}} \\
\hline & & \multicolumn{2}{|c|}{$\begin{array}{l}\text { Evaporative } \\
\text { mass model }\end{array}$} & \multicolumn{2}{|c|}{$\begin{array}{c}\text { Turbulence } \\
\text { model }\end{array}$} & & & & \\
\hline & & Pred. & $\begin{array}{c}\mathrm{AAD} \\
\%\end{array}$ & Pred. & $\begin{array}{c}\mathrm{AAD} \\
\%\end{array}$ & Pred. & $\begin{array}{c}\text { AAD } \\
\%\end{array}$ & Pred. & $\begin{array}{c}\mathrm{AAD} \\
\%\end{array}$ \\
\hline $\begin{array}{c}\mathrm{M} w \\
\left(\mathrm{Kg} / \mathrm{m}^{2}\right. \\
\text {.d) }\end{array}$ & 2.606 & 2.743 & 5.26 & 2.899 & 11.24 & 0.865 & 66.81 & 0.34 & 87.11 \\
\hline $\begin{array}{l}\eta \text { thed } \\
(\%)\end{array}$ & 40.17 & 42.23 & 5.13 & 44.63 & 11.10 & 13.61 & 66.12 & 5.17 & 87.13 \\
\hline
\end{tabular}

\section{4-2. Still Heat Transfer Coefficients:}

The data of Fig. 2 were also used to calculate the convective and evalporative heat-transfer rates between water and glass cover with the aid of eqns (16) and (23). The calculated values of evaporative, convective and radiative heat transfer coefficients were obtained using equs (14), (17) and (22), respectively. Figure 5 shows the heat flow rates in the solar still as a function of basin water temperature. Figures 6,7 and 8 illustrate the hourly variation of the heat transfer coefficients within the still enclosure using different models. It is clear that the evaporative mass transfer rate is strongly influenced by the evaporative heat transfer rate and it increases when the evaporative heat transfer late is increased. This can be observed when the corresponding values of Mw and qew shown in Figs. 3 and 6 are compared. It is also seen that the evaporative heat transfer coefficient has a maximum value around the noon period and reaches to about $80 \%$ of the total heat transfer coefficient, while the convective mode has a minimum value and represents about $6 \%$ at the same period. The radiative heat transfer mode dominates at low water temperatures up to $35^{\circ} \mathrm{c}$ between $9 \mathrm{~A}$. M. and $10 \mathrm{~A}$. M. and have higher values than the convective mode for all water temperature ranges, Fig 5 and 6. For water temperatures above 35 'c the cvaporative heat transfer coefficient exceeds the radiative mode. This situation characterized the water temperature building up the period in the still. Figure 8 shows that the calculated values of radiative heat transfer cocfficients using McAdams and Adhikari models increase mipilly to very high rates resulted in overprediction. It is expected that 
the use of different models, will cause an opposite change in the value of $\Delta \mathrm{T}$ to compensate the effect of convective heat transfer coefficient. This is to satisfy the heat transfer coefficient defined by eqn (17) and energy balance defined by eqns (33) (36) and (37), which explains the significant change in models predictions. However, the individually modes of heat transfer predicted by the evaporative mass model was still in a reasonable agreement with the experimental data.

The data of Figs. 6, 7 and 8 with the aid of eqn (32) were used to calculate the internal heat transfer coefficient between water and glass cover Ui. Figure 9 shows the experimental and predicted results in comparison with McAdams and Adhikari models. It is observed that both of the proposed models exhibit quite the same trend and the same feature. The same trend also agrees with McAdams and Adhikari models but with underprediction. However, the proposed model showed a deviation for Ui compared with the experimental data particularly at noon period. The results indicate that the maximum solar energy incident on the cover surface occurs at $15 \mathrm{P}$. M. This time corresponds to the maximum quantity of heat loss to environment due to both convection and radiation. On the other hand, this deviation resulted from the lumped error for each mode of heat transfer involved in Ui. The average absolute deviations between the measured and predicted results using the evaporative mass and turbulence models were 18.4 and $20.1 \%$ respectively, while these values reached to 51.7 and $68.3 \%$ for McAdams and Adhikari models, respectively.

\section{4-3. Still Overall Upward Heat Flow Factor:}

The overall upward heat flow factor Ut between water and environment was calculated utilizing the data given in Fig. 9. In Figure 10, the results are graphically presented. As can be seen, the predicted values of Ut using the evaporative mass and turbulence models represent the experimental data reasonably well. The average absolute deviations for proposed models were 3.6 and $4.0 \%$ respectively, while the calculated values using McAdams and Adhikari models were 17.6 and $30.7 \%$, respectively.

\section{4-4. Still Efficiency:}

The instantaneous still efficiency was calculated by dividing the evaporative heat transfer rate by the corresponding value of solar radiation intensity. The energy fraction transferred by evaporation and defined by eqn (28) represents the internal efficiency of the still. Equation (47) was used to predict the daily operational efficiency. Figure 
11 shows the hourly variation of still efficiency using the four models. The evaporative mass and turbulence models gave a reasonable agreement with experiments, except for some periods during the daytime. This disagreement between the measured and calculated results is due to the cover losses to ambient at a variable wind speed as discussed previously, a factor which ranges between $22.5 \%$ and $70 \%$ of the solar radiation intensity. On the other hand, the evaporative heat transfer rate and still efficiency are related. Therefore, any variation in the value of evaporative heat transfer rate will be accompanied by a corresponding change in both of the heat transfer losses to environment and still efficiency, a condition required by the energy balance and still efficiency equations. However, a tendency for the low prediction of still efficiency using McAdams and Adhikari models is again evident in Fig. 11. The results indicate that the maximum experimental values of still efficiency reaches to $53.7 \%$ at noon, while the daily operational efficiency is $\mathbf{4 0 . 1 7}$ $\%$. In Table 3 , the daily efficiency and average absolute deviations for different models are given.

\section{4-5. Basin Water and Glass Cover Temperatures:}

Verification of the model with outdoors transient measurements was also made from the measured values of basin water and glass cover temperatures. The results are shown in Figs. 12 and 13 for different models. The agreement between the measured and predicted basin water and glass cover temperatures using evaporative mass and turbulence models was reasonable, while the McAdams and Adhikari models overpredicted the temperature measurements. The average absolute deviations between the measured and predicted basin water and glass cover temperatures for different models are given in Table 3.

Table 3: The average absolute deviations between the measured and predicted basin water and glass cover temperatures.

\begin{tabular}{|c|c|c|c|c|}
\hline \multirow{3}{*}{ Temp. } & \multicolumn{2}{|c|}{ Present models } & \multirow{2}{*}{$\begin{array}{l}\text { McAdams } \\
\text { model }\end{array}$} & \multirow{2}{*}{$\begin{array}{c}\text { Adhikari } \\
\text { model }\end{array}$} \\
\hline & $\begin{array}{l}\text { Evaporative } \\
\text { mass model }\end{array}$ & $\begin{array}{c}\text { Turbulence } \\
\text { model }\end{array}$ & & \\
\hline & \multicolumn{4}{|c|}{ AAD \% } \\
\hline Tw & 4.9 & 6.1 & 20.8 & 28.1 \\
\hline Tg & 5.6 & 7.0 & 23.5 & 30.9 \\
\hline
\end{tabular}

It is evident that the predicted mass evaporative rate, internal heat transfer coefficients between water and glass cover, overall upward heat flow factor and thermal efficiency are sensitive to the heat transfer correlation used. The McAdams and Adhikari correlations usually lead to underprediction of these parameters, whereas the turbulence 
cover temperatures have the predictions inverted. The evaporative mass model developed in this work provides better prediction for the still performance. It may be useful in designing new units for utilizing solar energy in Egyptian desert or remote regions.

\section{5- CONCLUSIONS:}

Experimental data for the water evaporative mass transfer rate, heat transfer coefficient, thermal efficiency, basin water and glass cover temperatures of solar distillation unit have been compared with the predictions of evaporative mass and turbulence models during the transient operation conditions. The predictions of still performance are sensitive to the heat transfer correlation used. The predictions of the evaporative mass model are found to exhibit trends, which are consistent with those of the experimental data and give better prediction for the still performance compared with the turbulence model. The proposed empirical correlation used in the evaporative mass model is: $\mathrm{Nu}=0.669(\mathrm{Ra})^{0.3322}$ for Grashof number ranging from $5.13 \times 10^{3}$ to $2.10 \times 10^{5}$. The Turbulence model with a new constant $C$ of 0.699 leads to overprediction, except for the case of basin water and glass cover temperatures. The McAdams and Adhikari models lead to underprediction of the performance and may not be used to describe the conditions inside the still in regions like Egypt.

\section{NOMENCLATURE:}

Ag area of glass plate, $\mathbf{m}^{2}$.

Ar. glass plate to water surface area ratio, dimensionless.

Aw horizontal free surface area of water in the basin, $\mathrm{m}^{2}$.

$C, n$ empirical constants used in eqn (26).

$\mathrm{Cg}$ heat capacity of glass cover per unit area, $\mathrm{J} / \mathrm{m}^{2} .^{0} \mathrm{c}$.

$\mathrm{Cp}$ specific heat capacity of humid air, $\mathrm{J} / \mathrm{kg} .{ }^{\circ} \mathrm{c}$.

$\mathrm{Cw}$ heat capacity of water in the still per unit area, $J / \mathrm{m}^{2} .0$.

df average spacing between water surface and glass cover, $\mathbf{m}$.

g acceleration due to gravity, $\mathrm{m} / \mathrm{sec}^{2}$.

fee energy fraction transferred by evaporation, dimensionless.

fec energy fraction transferred by convection, dimensionless.

fer energy fraction transferred by radiation, dimensionless.

Gr Grashof number, dimensionless

hb heat transfer coefficient through base and sides, $w / m^{2} .{ }^{o} c$.

hcw convective heat transfer coefficient, $w / m^{2} .^{o} c$.

hew evaporative heat transfer coefficient, $w / m^{2} .0$. 
hrw radiative heat transfer coefficient $w / m^{2} . c$.

hrgs radiative heat transfer coefficient, outside the still, $w / m^{2} . c$.

hw wind heat transfer coefficient, $w / m^{2} .0$.

Hs solar radiation intensity, $w / m^{2}$.

kf thermal conductivity of humid air, w/m. ${ }^{0}$.

hfg latent heat of humid air, J/kg.

Mw evaporative mass transfer rate, $\mathrm{kg} / \mathrm{m}^{2} \mathrm{hr}$.

$\mathrm{Nu} \quad$ Nusselt number, dimensionless.

$\mathrm{Pg}$ partial pressure of water vapour at the glass cover temperature, $\mathrm{N} / \mathrm{m}^{2}$.

Pw partial pressure of water vapour at the basin temperature, $\mathrm{N} / \mathrm{m}^{2}$.

Pr Prandtl number, dimensionless.

$q \mathrm{cw}$ convective heat transfer rate from water to the glass surface, $\mathbf{w} / \mathbf{m}^{2}$.

qew evaporative heat transfer rate from water to the glass surface, $\mathbf{w} / \mathbf{m}^{2}$.

qrw radiative heat transfer rate from water to the glass surface, $w / m^{2}$

$R \quad$ parameter defined by eqn. (27).

Ra Rayleigh number, dimensionless.

$\mathbf{R a}^{i} \quad\left(\frac{\rho \mathrm{g} \beta \mathrm{Cp}}{\mu}\right) \Delta \mathrm{T}^{1 / 3}$ modified Rayleigh number, $\mathbf{w} / \mathbf{m}^{2}{ }^{\circ} \mathrm{c}$.

Ta ambient temperature, ${ }^{\circ} \mathrm{c}$.

$\mathrm{Tg}$ glass cover temperature, ${ }^{\circ} \mathrm{c}$.

Ts equivalent black body sky temperature, ${ }^{\circ} \mathrm{c}$.

Tw basin water temperature, ${ }^{0} \mathrm{c}$.

Ui heat transfer coefficient between water and glass cover, w/m ${ }^{2} .^{0} \mathrm{c}$.

Uo heat transfer coefficient between glass cover and environment, $\mathbf{w} / \mathbf{m}^{2} \cdot{ }^{\circ} \mathbf{c}$.

Ut overall upward heat flow factor between water and environment, $\mathbf{w} / \mathbf{m}^{2} . \mathbf{c}$.

AAD $\frac{1}{N} \sum \frac{\mathrm{Mw}, \text { pred }-\mathrm{Mw} \text {, meas }}{\mathrm{Mw}, \text { meas }} \times 100$, average absolute deviation, percentage.

$N$ number of data points.

\section{Greek symbols:}

$\Delta \mathrm{T}^{\prime} \quad$ effective temperature difference as defined by eqn (20), ${ }^{0} \mathrm{c}$.

$\Delta \mathrm{T} \quad$ basin water to glass cover temperature difference, ${ }^{\circ} \mathrm{c}$.

$\beta \quad$ coefficient of volumetric thermal expansion, $1 /{ }^{\circ} \mathrm{K}$ 
$\rho$ density of humid air, $\mathrm{kg} / \mathrm{m}^{3}$.

$\sigma \quad$ Stefan-Boltzman constant, $5.67 \times 10^{-8} \mathrm{w} / \mathrm{m}^{2} \mathrm{~K}^{4}$.

$\eta$ thd still daily thermal efficiency, percentage.

\section{REFERENCES:}

1-Solar distillation as a means of meeting small-scale water demands, Department of Economic and Social Affairs, United Nations Report, United Nations, New York, PP. 1-86, 1978.

2-Jacob, M. Heat transfer, Wiley \& Sons, New York, Vol. 21957.

3-McAdams, W. C., Heat Transmission, 3rd edition, McGraw Hill, New York, 1954.

4-Dunkle, R. V., Solar water distillation, The roof type still and multiple effect diffusion still, Int. Heat Transfer Conf., Part V, Develop. Heat Transfer, University of Colorado, Boulder, California, U. S. A., PP. 895-902, 1961.

5-Tiwari, G. N. and Lawrence, S. A., New heat and mass transfer relations for a solar still, Energy Conversion Management, 31, PP. 201-203, 1991.

6-Adhikari, R. S. and Kumar, A., Estimation of mass transfer rates in solar stills, Energy Research, No: 14, PP. 737-744, 1990.

7-Adhikari, R. S., Kumar, A. and Sootha, G. D., Simulation studies on a multi-stage stacked tray solar still, Solar Energy, Vol. 54, No: 5, PP. 317-325, 1995.

8-Shawaqfeh, A. T. and Farid, M. M., New development in the theory of heat and mass transfer in solar stills, Solar Energy, Vol. 55, No: 6, PP. 527-535, 1995.

9-Kumar, S. and Tiwari, G. N., Estimation of convective mass transfer in solar distillation systems, Solar Energy, Vol. 57, No: 6, PP. 459-464, 1996.

10-Malik, M. A. S., Tiwari, G. N., Kumar, A. and Sodha, M. S., Solar Distillation, Pergamon Press, Oxford, 1982.

11-Clark, J. A., The steady state performance of a solar still, Solar Energy, Vol. 44, No: 1, PP. 43-49, 1990.

12-Zaki, G. M., Radhwan, A. M. and Balbeid, A. O., Analysis of assistedcoupled solar stills, Solar Energy, Vol. 51, No: 4, PP. 277-288, 1993.

13-Yunus A. Cenegl., Heat transfer: a practical approach, McGraw-Hill, New York, 1998.

14- Rai, G. D., Solar energy utilization, Khanna Publishers, Delhi, 1984.

15-Sharma, V. B. and Mullick, S. C., Calculation of hourly output of a solar still, Journal of Solar Energy Engineering, November 1993, Vol. 115, PP. 231-236, 1993. 


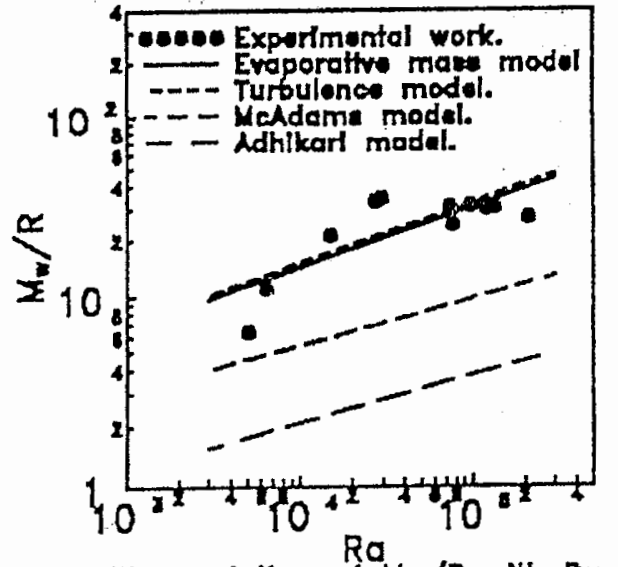

Fig.2: The vartation of $\mathrm{Nw} / \mathrm{R}$ with $\mathrm{Ra}$ using the four modely.

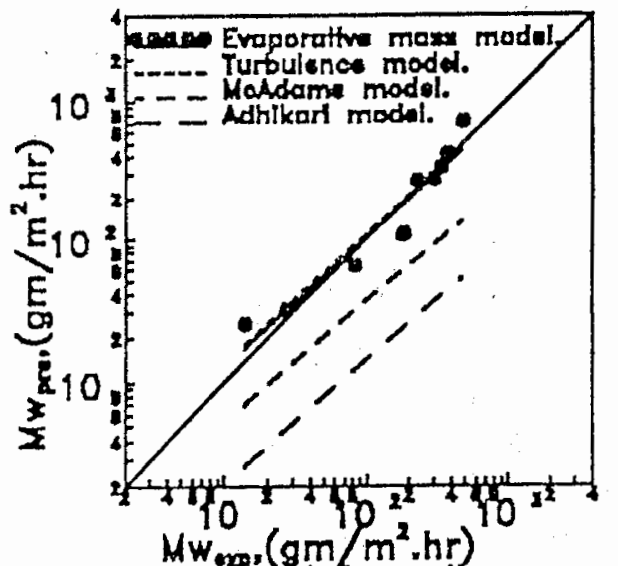

Fla.4: Comportion botween the madsured and pradlefed ovoporatlve mosis transtor rate ueing different modis.

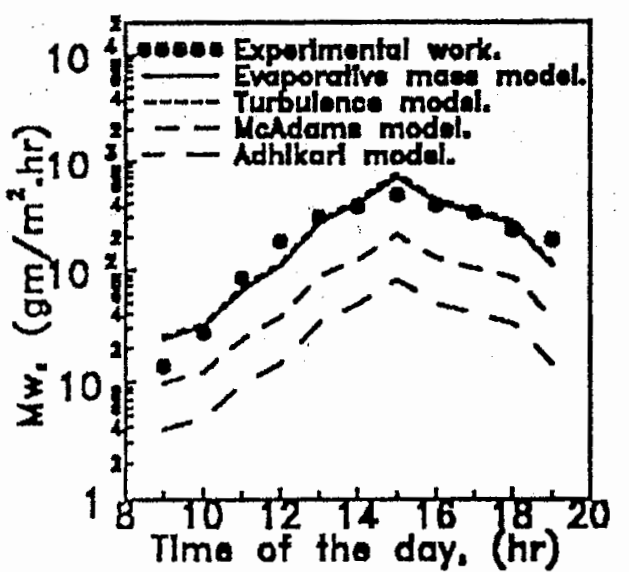

Flg.J: Hourty masurad and predleted -vaporative masa transtar rate using the four modals.

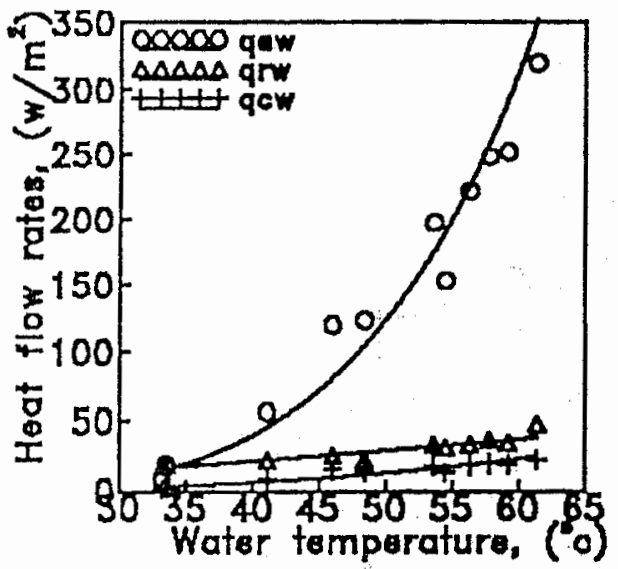

Flg.5: The hoat flow rates in the solar still as a function of basin woter temperatura. 


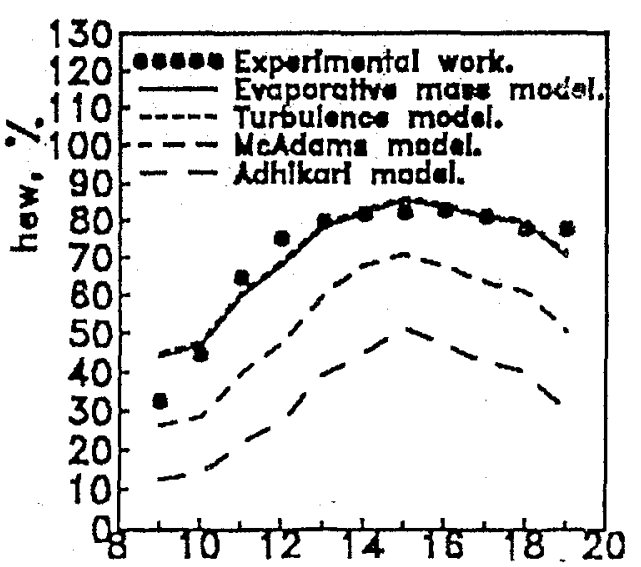

Tlme of the day, (hr)

Flg.6: Hourty evaporative hoat transfor coofflolont betwoon wator and glaza covar.

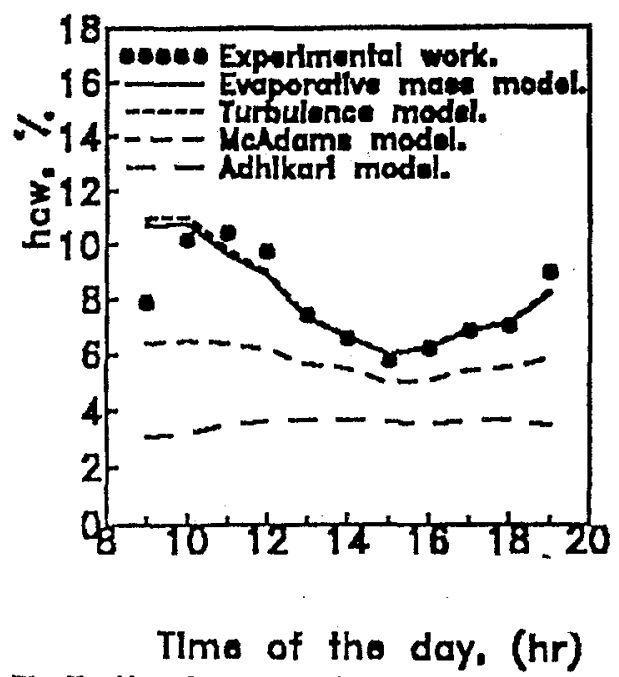

FIg.7: Hourly convectlve heaf tranafor ooefficlont botween water and glass cover.

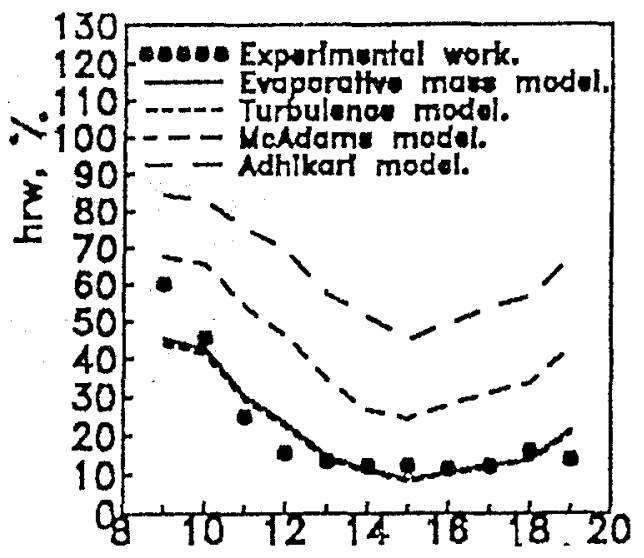

Tlms of the doy, (hr)

Fig.8: Hourty radlative hoot transfor corificisnt botwean water and glaes covar.

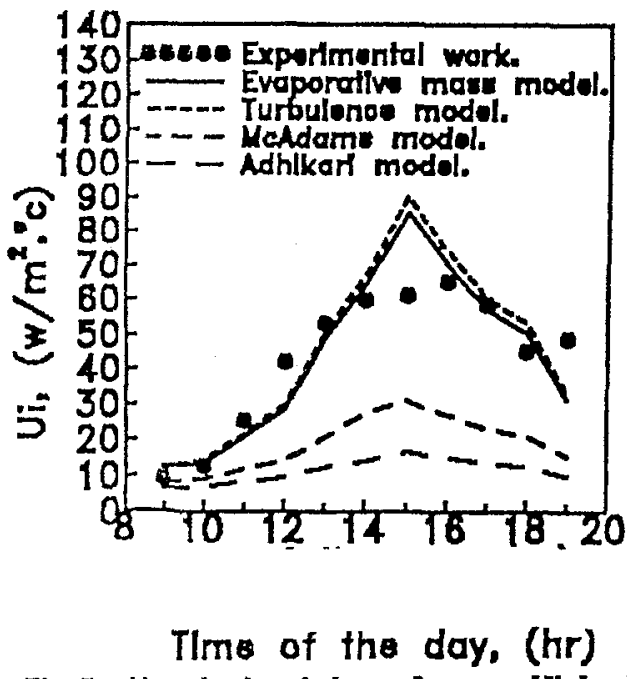

Flg.9: Hourly heat transfor ooofflolent butwenn woter and glass cover. 


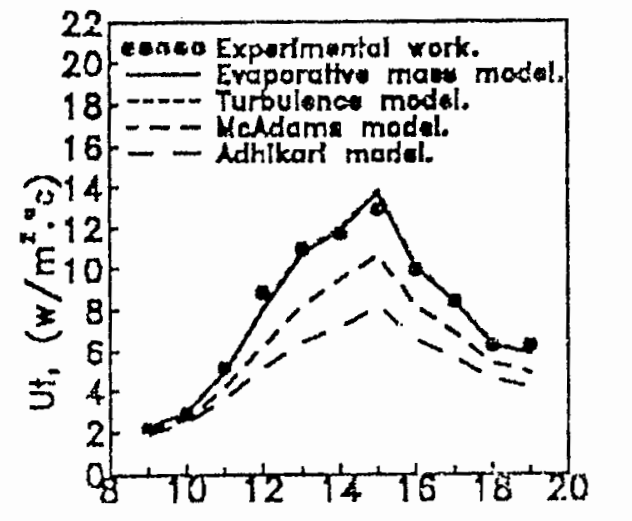

Mme of the day, (hr)

Fo.10: Overoll upward hegt flow factor betwean woter and environmnt.

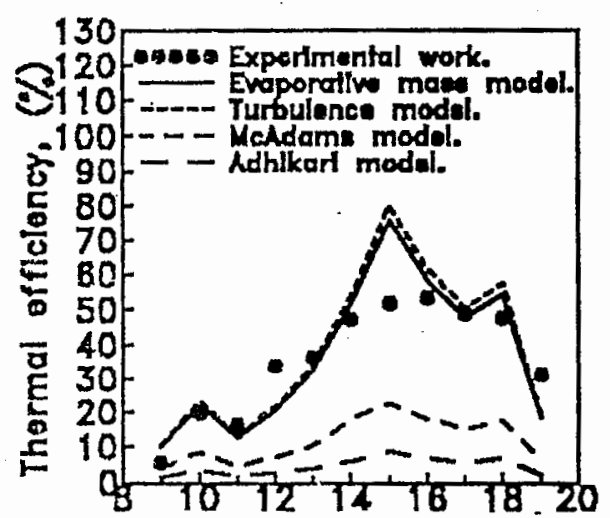

Tlms of the day, (hr) Fig. 11: Hourty variation of the ettil offloienoy uning the four models.

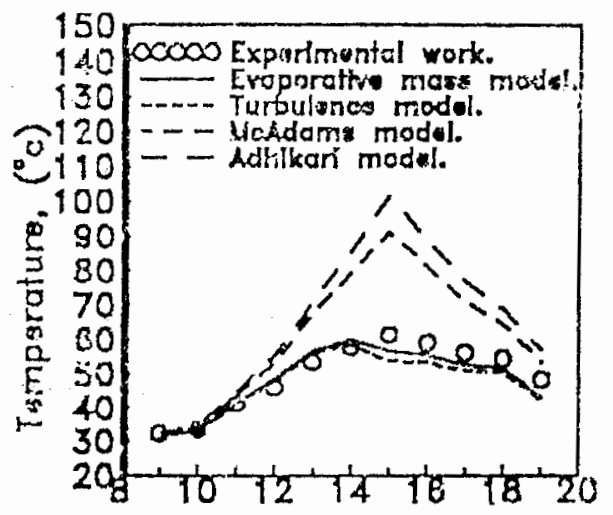

Time of the day, (hr)

Fig.12:Compurixon betwean the mecsured and pradleted water tamparature of zolar will ueling diffarant motiale.

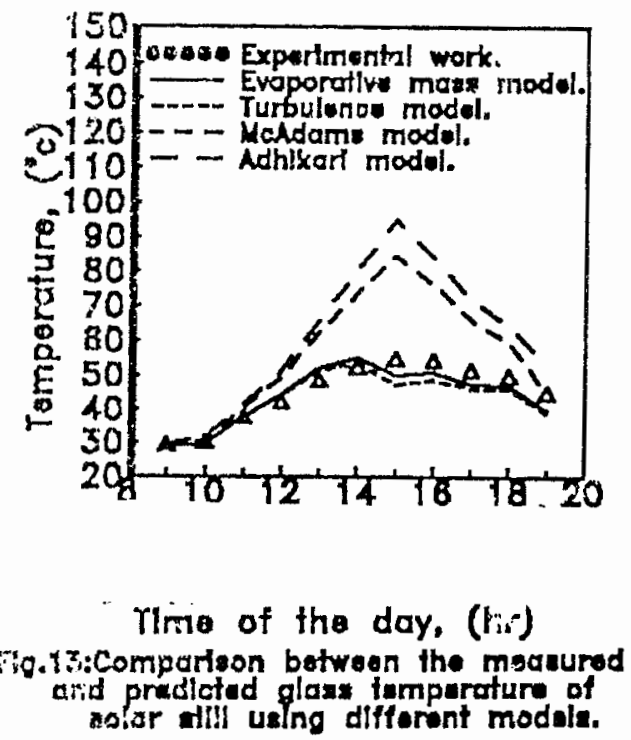


موديلات رياضيه للتنبَ بالاداء الحراري لوحدات التعطير الشمسي

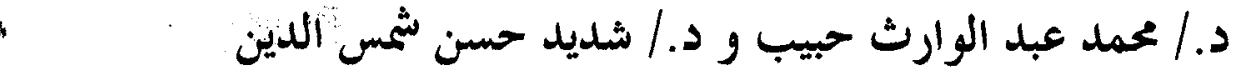

قسم هندسة القوي الميكانيكية-كلية المندسة بشبين الكوم-جامعة المنوفية

تم إنشاء مقطر تمسي من النوع ذو الحوض المفرد الغطاء مساحة سطحه الماص للحســرارة

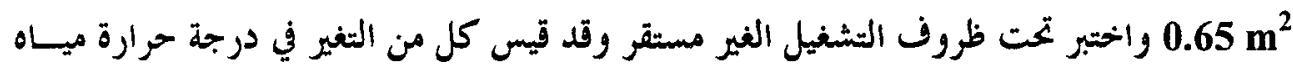

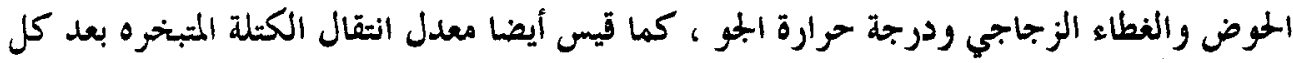

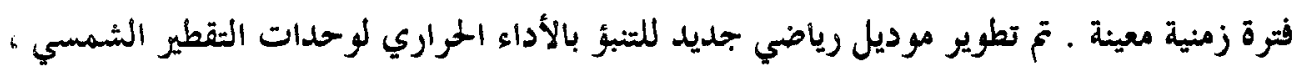

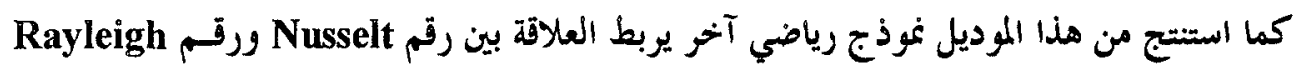

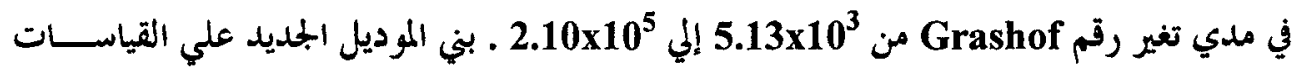

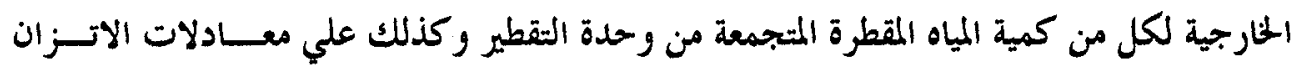

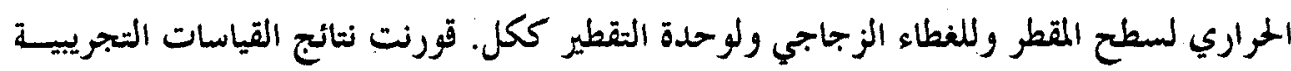

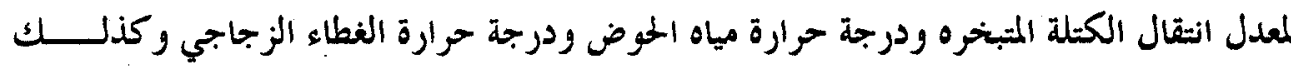

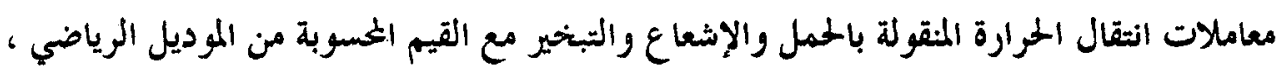

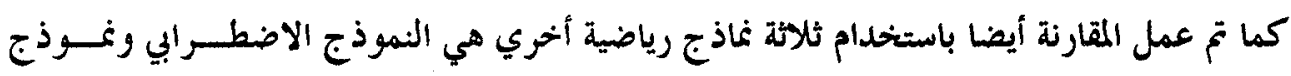
Adhikari ونوذج McAdams

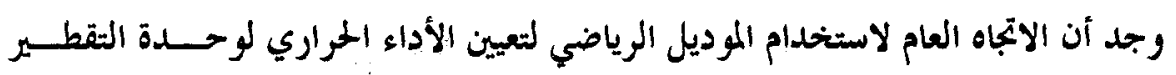

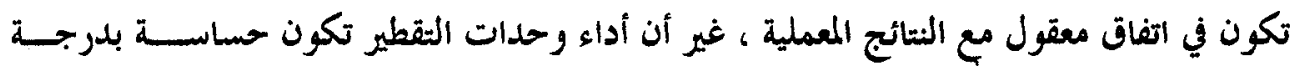

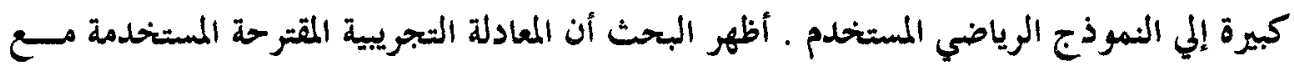
موديل الكتلة المتبخروه تكون : Nu=0.669Ra . Nu=0.699Ra ${ }^{1 / 3}$

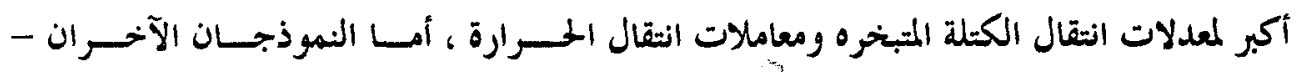

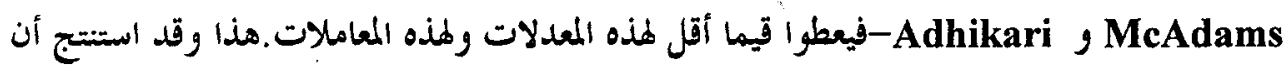

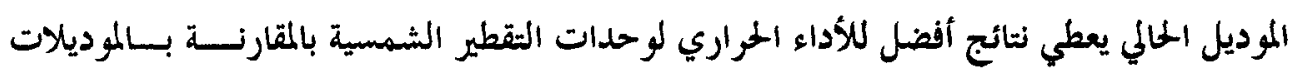

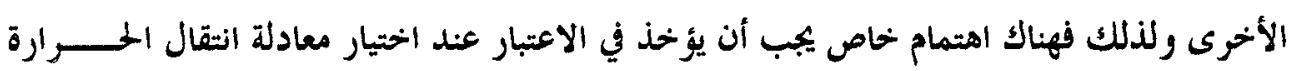
المستخدمة في تعيين الأداء الحراري لوحدات التهات التقطير الشمسي. 